Article

\title{
Effect of Oral Choline Alfoscerate on Patients with Keratoconjunctivitis Sicca
}

\author{
Jin Ju Choi ${ }^{\dagger}$, Jin Sun Hwang ${ }^{\dagger}$ and Young Joo Shin * \\ Department of Ophthalmology, Hallym University Medical Center, Hallym University College of Medicine, \\ Seoul 150-719, Korea; 920128@hallym.or.kr (J.J.C.); hotsayme@naver.com (J.J.H.) \\ * Correspondence: schinn@hanmail.net \\ t These authors contributed equally to the work.
}

Received: 7 April 2020; Accepted: 21 May 2020; Published: 23 May 2020

\begin{abstract}
Keratoconjunctivitis sicca (KCS) or dry eye is a disease characterized by ocular surface symptoms. This study aimed to investigate the effectiveness of oral choline alfoscerate (CA) administration as a treatment for KCS. The medical records of dry eye patients who were refractory to topical eyedrops and then took oral CA were reviewed. Results of tear break-up time (TBUT), fluorescein ocular surface staining score (FSS), and tear secretion by the Schirmer test (STT) were analyzed. The results of the ocular surface disease index (OSDI), visual analog pain score (VAS), reporting of the severity and frequency of symptoms, and the modified Standardized Patient Evaluation of Eye Dryness (SPEED) questionnaire were also analyzed. The records of 47 patients were analyzed for this study. The mean age was $62.8 \pm 9.3$ years, and the patients included 9 males and 38 females. TBUT, OSDI, and VAS significantly improved after CA administration compared to before $(p<0.05$, paired $t$-test). After CA administration, symptom frequency and impact on life improved $(p<0.05$, paired $t$-test). No significant change in photophobia or FSS was identified. In conclusion, oral CA administration was effective in improving tear stability and alleviating symptoms of KCS.
\end{abstract}

Keywords: choline alfoscerate; keratoconjunctivitis sicca; tear break-up time; dry eye symptoms

\section{Introduction}

Keratoconjunctivitis sicca (KCS) or dry eye is a disease characterized by ocular surface symptoms, including grittiness, pain, burning, stinging, foreign body sensation (FBS), and photophobia. However, dry eye is a disease in which the amount of tears present on the ocular surface is insufficient because of excessive evaporation or low tear secretion [1]. KCS symptoms result from a reduction in both the quantity and quality of tear production. Therapy for KCS includes artificial tear application and topical administration of the bioactive drugs diquafosol and cyclosporine A (CsA) [2]. Punctal plugs can be used to increase tear retention [2]. Despite improvement of the tear film and ocular surface characteristics, KCS symptoms often do not respond to treatment [3]. Recently, a neuropathic mechanism has been implicated as one cause for this [3].

Aging is an identified risk factor for KCS [4] as is cholinergic innervation loss [5]. However, significant cholinergic cell loss during aging as a cause of KCS has been challenged [6]. Acetylcholine is the primary parasympathetic neurotransmitter [7]. The parasympathetic innervation of the lacrimal apparatus is supplied by the petrosal nerve [8]. The secretion of proteins, electrolytes, and water by the lacrimal gland depends on neurotransmitters (acetylcholine and norepinephrine) released by the activation of either the parasympathetic or sympathetic nerves [8]. The meibomian glands and conjunctival goblet cells have muscarinic receptors $[9,10]$.

Choline is an essential nutrient, and it can be acquired from the diet [11]. Choline alfoscerate (CA), also called alpha glycerylphosphorylcholine, is a natural choline compound and a parasympathomimetic 
acetylcholine precursor [12]. Phosphatidylcholine has been proposed to potentiate the synthesis of acetylcholine [12]. Phosphatidylcholine is thought to have therapeutic potential in patients with peripheral neuropathy and brain injury because of its antioxidant properties and ability to modulate microglial activity [13]. The analgesic effect of phosphatidylcholine is induced by stimulation of muscarinic receptors, and its anti-neuropathic effect is mediated via stimulation of nicotinic receptors [14]. Choline supplementation could improve the symptoms of KCS; however, this has not been previously reported. In this study, we investigated the effect of oral choline alfoscerate administration on patients with KCS.

\section{Methods}

This retrospective cohort study was approved by the Hallym University Medical Center Institutional Review Board and was carried out following the principles of the Declaration of Helsinki. Between January 2015 and May 2019, patients with KCS symptoms refractory to topical treatment were prescribed oral administration of CA. Records of these patients were reviewed; patients were included in the study if they met the following inclusion criteria: Older than 45 years of age; presence of clinical signs and symptoms of KCS; presence of symptoms refractory to treatment with artificial tears, bioactive drugs, and punctal plug; and clinical examination variable assessments and survey completions prior to two weeks and/or six weeks after commencing oral CA. Topical treatments were prescribed continuously.

Clinical endpoints included tear break-up time (TBUT), lid hyperemia, ocular surface disease index (OSDI), visual analog pain score (VAS), symptom scores, fluorescein ocular surface staining score (FSS), and Schirmer tear test (STT). Patients were asked to provide a VAS and complete a modified Standardized Patient Evaluation of Eye Dryness (SPEED) questionnaire. TBUT was measured using fluorescein staining strips. FSS was graded using the Oxford grading scale [15]. OSDI was calculated after patient OSDI questionnaire completion [16]. VAS was assessed using a segmental numerical technique [17].

A modified SPEED was used to assess the frequency and severity of each symptom, including dryness, foreign body sensation, coldness, eye fatigue, pain, and photophobia [18]. The SPEED questionnaire was scored for both frequency of symptoms $(0=$ no symptoms, $1=$ sometimes, $2=$ often, and $3=$ constant $)$ and severity of symptom/impact on daily life $(0=$ no symptoms, $1=$ tolerable but not uncomfortable, 2 = uncomfortable but does not interfere with my day, $3=$ bothersome and interferes with my day, and $4=$ intolerable and unable to perform my daily tasks).

\section{Statistical Analysis}

Only one eye in each patient was evaluated. A mixed-effects model analysis was performed using Graphpad Prism 8.2 (GraphPad Software, San Diego, CA) to examine time-related changes of parameters. Paired $t$-tests were used to examine differences in the parameters between each time point using Statistical Package for Social Sciences (SPSS) software (version 24, PSS, Inc, Chicago, IL, USA). Statistical significance was defined as $p<0.05$. A Wilcoxon signed-rank test instead of the paired $t$-test was used for the nonparametric statistical analysis.

\section{Results}

In total, 47 eyes of 47 patients were included. Nine males and 38 females with a mean age of $62.8 \pm 9.3$ years were enrolled. Forty-four patients returned two weeks after commencing oral CA, and 32 patients returned six weeks after commencing oral CA. Before commencing oral CA, mean TBUT was $5.9 \pm 2.7 \mathrm{~s}$, FSS was $0.27 \pm 0.61$, lid hyperemia was $1.5 \pm 0.9$, tear secretion was $8.8 \pm 7.0 \mathrm{~mm}$, OSDI was $1.1 \pm 24.3$, VAS was $3.2 \pm 2.5$, impact of dry eye symptoms on daily life was $2.8 \pm 0.9$, and daily frequency was $2.7 \pm 1.0$ (Table 1 ). The severity and frequency of each symptom before taking oral CA are described in Tables 2 and 3. 
Table 1. Signs and symptoms change before and after taking oral choline alfoscerate.

\begin{tabular}{cccc}
\hline & $\begin{array}{c}\text { Before Taking Oral } \\
\text { Choline Alfoscerate }\end{array}$ & $\begin{array}{c}\text { Two Weeks after Taking } \\
\text { Oral Choline } \\
\text { Alfoscerate }\end{array}$ & $\begin{array}{c}\text { Six Weeks after Taking } \\
\text { Oral Choline } \\
\text { Alfoscerate }\end{array}$ \\
\hline N & 47 & 44 & 32 \\
Age (y) & $62.8 \pm 9.3$ & $62.9 \pm 9.1$ & $61.9 \pm 8.9$ \\
Male:female & $9: 38$ & $8: 36$ & $5: 27$ \\
TBUT (s) & $5.9 \pm 2.7$ & $7.2 \pm 2.9 *$ & $7.5 \pm 2.6^{*}$ \\
FSS & $0.27 \pm 0.61$ & $0.26 \pm 0.53$ & $0.27 \pm 0.57$ \\
Lid hyperemia & $1.5 \pm 0.9$ & $1.3 \pm 0.9+$ & $1.1 \pm 0.9+$ \\
OSDI & $51.1 \pm 24.3$ & $40.4 \pm 18.7^{*}$ & $36.2 \pm 16.4^{*}$ \\
VAS & $3.2 \pm 2.5$ & $2.1 \pm 1.8^{*}$ & $2.1 \pm 1.7$ \\
Impact on the daily life & $2.8 \pm 0.9$ & $2.5 \pm 1.0 \dagger$ & $2.4 \pm 0.8+$ \\
Daily frequency & $2.7 \pm 1.0$ & $2.2 \pm 1.1+$ & $1.9 \pm 0.9+$ \\
\hline
\end{tabular}

TBUT = tear break-up time; FSS = fluorescein staining score; OSDI = ocular surface disease index; VAS = visual analogue scale. ${ }^{*}<0.05$ by paired $t$-test.; $\dagger<0.05$ by Wilcoxon signed-rank-test.

Table 2. Changes of each symptom frequency before and after taking oral choline alfoscerate.

\begin{tabular}{cccc}
\hline & $\begin{array}{c}\text { Before Taking Oral } \\
\text { Choline Alfoscerate }\end{array}$ & $\begin{array}{c}\text { Two Weeks after Taking } \\
\text { Oral Choline } \\
\text { Alfoscerate }\end{array}$ & $\begin{array}{c}\text { Six Weeks after Taking } \\
\text { Oral Choline } \\
\text { Alfoscerate }\end{array}$ \\
\hline Dryness & $2.0 \pm 1.0$ & $1.8 \pm 0.9$ & $1.6 \pm 0.7+$ \\
FB sensation & $1.8 \pm 1.0$ & $1.6 \pm 0.9$ & $1.3 \pm 0.7 \dagger$ \\
Coldness & $1.4 \pm 1.1$ & $0.9 \pm 1.0+$ & $1.1 \pm 0.9 \dagger$ \\
Fatigue & $1.7 \pm 1.1$ & $1.4 \pm 0.9+$ & $1.6 \pm 0.7$ \\
Pain & $1.2 \pm 1.1$ & $0.7 \pm 0.7+$ & $0.8 \pm 0.7$ \\
Photophobia & $1.2 \pm 1.2$ & $1.2 \pm 1.1$ & $1.1 \pm 1.0$ \\
\hline
\end{tabular}

$+<0.05$ by Wilcoxon signed-rank-test.

Table 3. Changes of each symptom severity before and after taking oral choline alfoscerate.

\begin{tabular}{cccc}
\hline & $\begin{array}{c}\text { Before Taking Oral } \\
\text { Choline Alfoscerate }\end{array}$ & $\begin{array}{c}\text { Two Weeks after Taking } \\
\text { Oral Choline } \\
\text { Alfoscerate }\end{array}$ & $\begin{array}{c}\text { Six Weeks After Taking } \\
\text { Oral Choline } \\
\text { Alfoscerate }\end{array}$ \\
\hline Dryness & $2.3 \pm 1.1$ & $1.9 \pm 1.0+$ & $1.8 \pm 0.9+$ \\
FB sensation & $2.2 \pm 1.1$ & $1.9 \pm 1.1$ & $1.5 \pm 1.0 \dagger$ \\
Coldness & $1.5 \pm 1.1$ & $1.1 \pm 1.1+$ & $1.2 \pm 0.9+$ \\
Fatigue & $1.9 \pm 1.2$ & $1.4 \pm 1.0+$ & $1.5 \pm 1.0$ \\
Pain & $1.5 \pm 1.2$ & $1.1 \pm 1.1+$ & $1.0 \pm 0.9$ \\
Photophobia & $1.3 \pm 1.2$ & $1.2 \pm 1.1$ & $1.1 \pm 1.0$ \\
\hline
\end{tabular}

$+<0.05$ by Wilcoxon signed-rank-test.

Mixed effects model analysis identified an improvement in TBUT and lid hyperemia after commencing oral CA $(p<0.001$ and 0.005 ; Figure 1). OSDI, VAS, impact of dry eye symptoms, and daily frequency of dry eye symptoms decreased overtime $(p<0.001,0.019,0.022$, and $<0.001$; Figure 2$)$. Daily frequency of dryness, coldness, and pain decreased overtime ( $p=0.049,0.004$, and 0.010 ; Figure 3$)$. Severity of dryness, FBS, coldness, and fatigue decreased over time $(p=0.027,0.013,0.016$, and 0.026 ; Figure 4). 
A

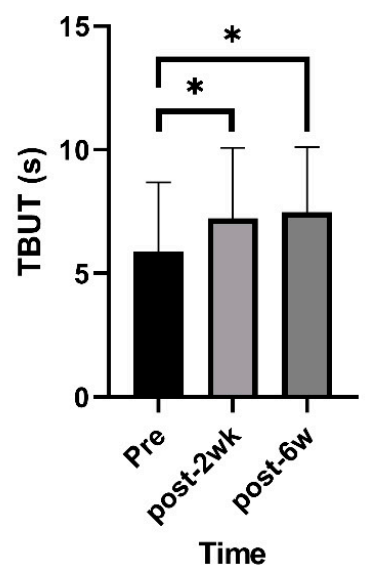

B

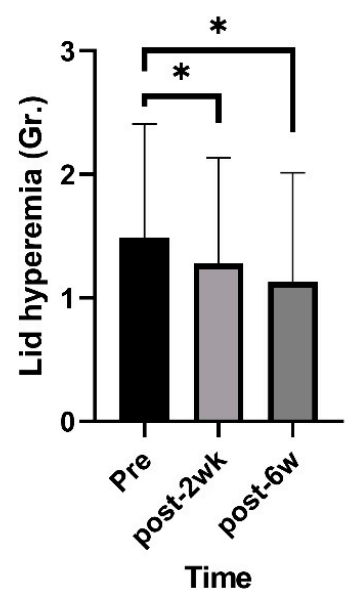

Figure 1. Changes of objective signs of dry eye disease over time. (A) Tear break-up time (TBUT) increased over time. (B) Lid hyperemia grade decreased over time. * statistically significant.

A

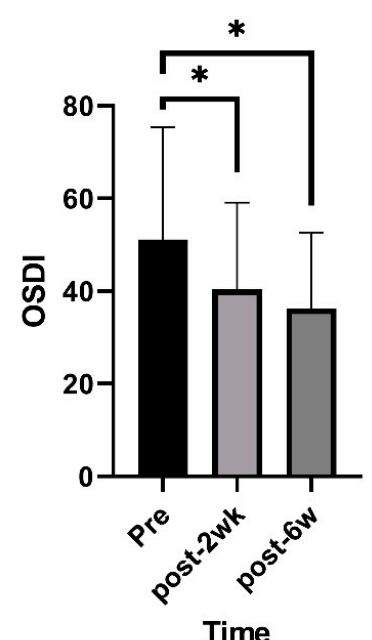

C

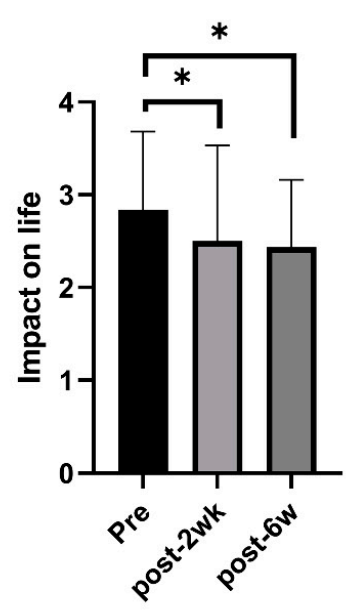

Time
B

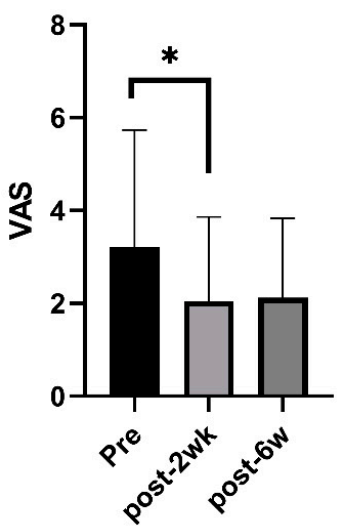

D

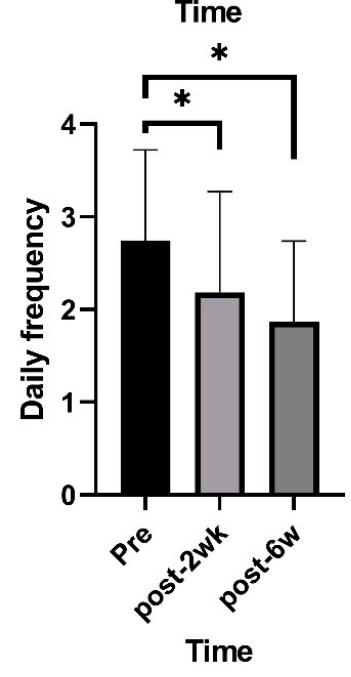

Figure 2. Changes of subjective symptoms of dry eye disease over time. (A,B) Ocular surface disease index (OSDI) and visual analogue pain score (VAS) decreased over time. (C,D) Impact of dry eye symptoms on life and daily frequency of dry eye symptoms decreased over time. * ${ }^{*}$ statistically significant. 
A

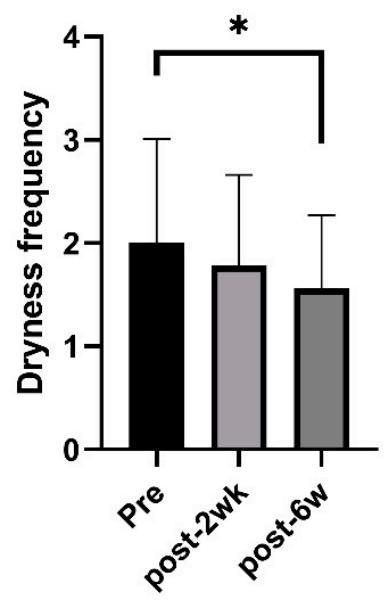

Time
B

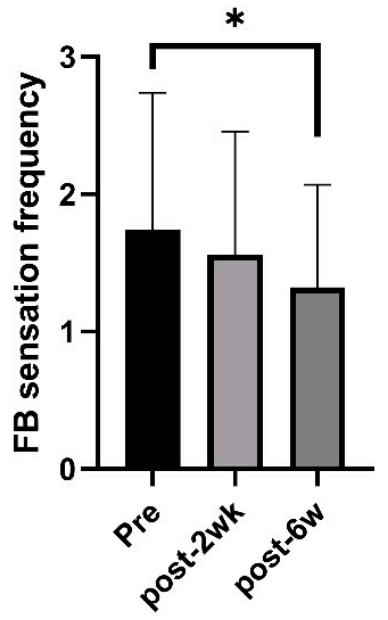

Time
C

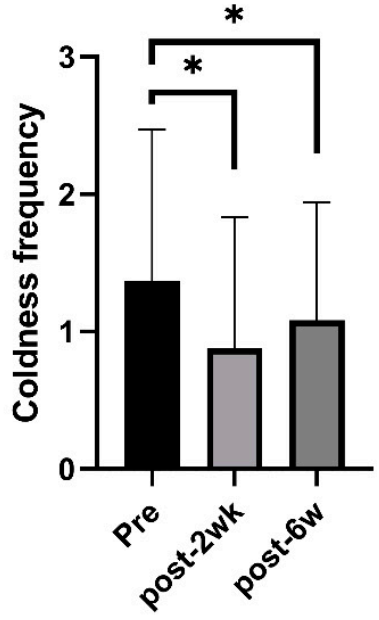

Time

D

$\mathrm{E}$
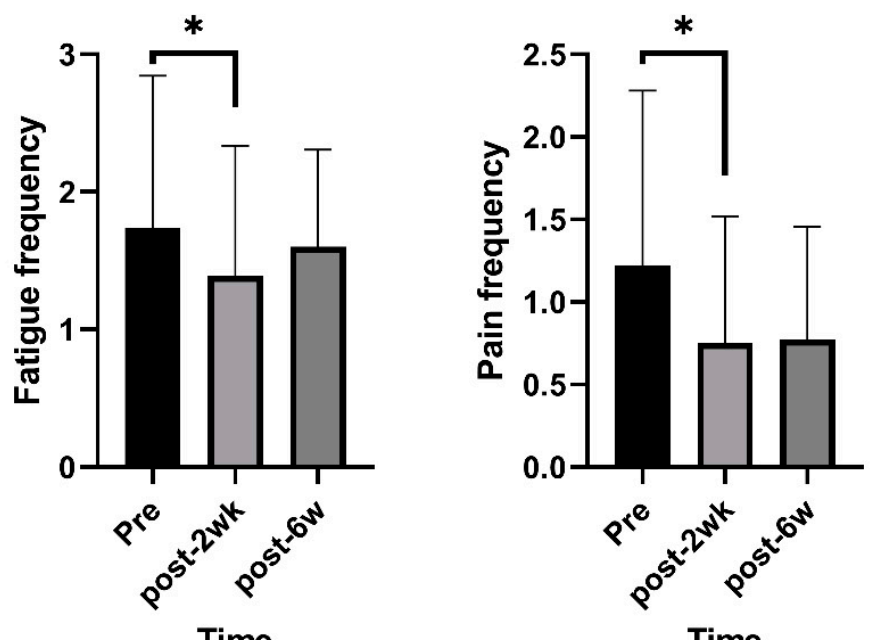

Time

Figure 3. Changes of frequency of individual symptoms over time. (A,B) Frequencies of dryness and foreign body sensation decreased over time. (C-E) Frequencies of coldness, eye fatigue, and pain changed over time. * statistically significant.

Two weeks after commencing oral CA, TBUT, OSDI, and VAS were improved compared to the baseline ( $p=0.001,0.003$, and 0.004, paired $t$-test; Table 1$)$, and lid hyperemia, impact of dry eye symptoms on life, and daily frequency was reduced compared to the baseline ( $p=0.014,0.034$, and 0.009 , Wilcoxon signed-rank test; Table 1). There were no significant changes in FSS and STT. After commencing CA, scores for daily frequency of coldness, fatigue, and pain were reduced $(p=0.003$, 0.010, and 0.003, Wilcoxon signed-rank test; Table 2), and scores for the severity of dryness, coldness, fatigue, and pain were improved ( $p=0.008,0.019,0.004$, and 0.044 , Wilcoxon signed-rank test; Table 3$)$. 
A

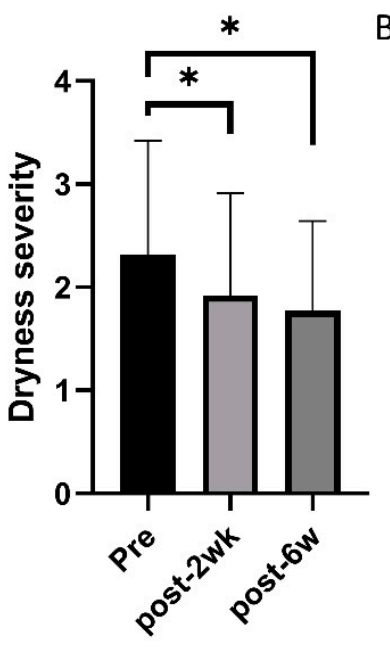

Time
B

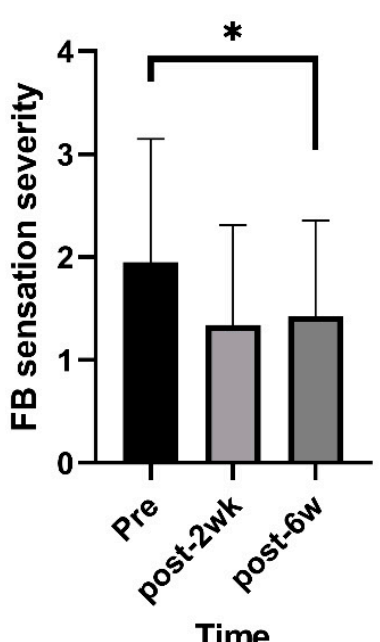

Time

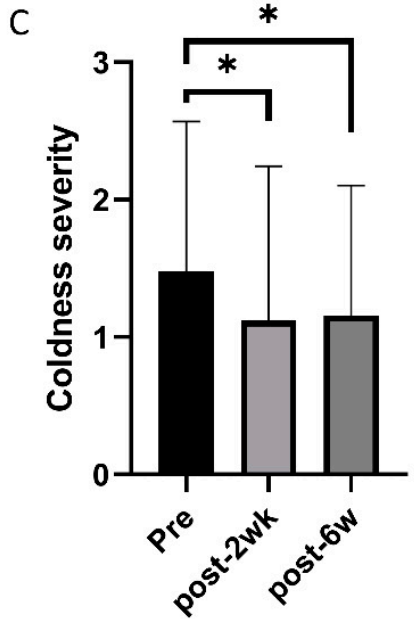

Time
D

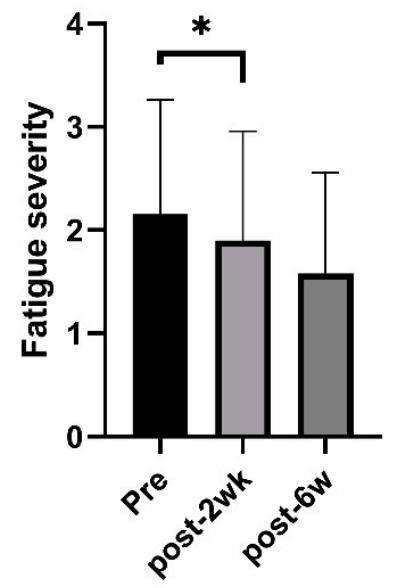

Time
$\mathrm{E}$

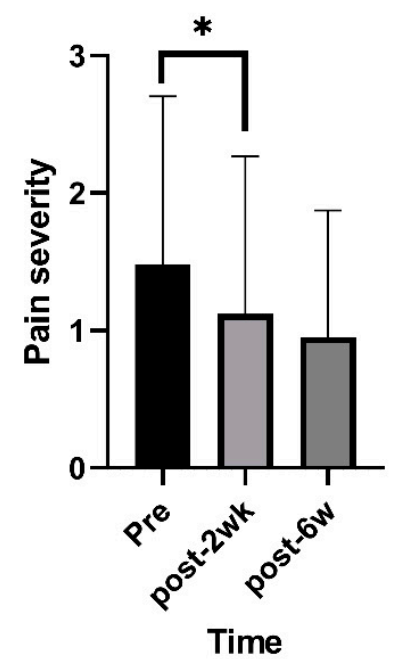

Figure 4. Changes of severity of individual symptoms over time. (A-C) Severity of dryness, foreign body sensation, and coldness decreased over time. (D) Severity of eye fatigue and pain changed over time. * statistically significant.

Six weeks after commencing oral CA, TBUT and OSDI had improved compared to the baseline ( $p=0.001$, and 0.004 , paired $t$-test; Table 1$)$, and lid hyperemia, impact of dry eye symptoms on life, and daily frequency were reduced compared to the baseline $(p=0.016,0.011$, and 0.002 , Wilcoxon signed-rank test; Table 1). FSS and STT were not statistically different from the pretreatment values. Each symptom was also evaluated. Daily frequency of dryness, FB sensation, and coldness were reduced compared to pretreatment values $(p=0.001,0.026$, and 0.036 , Wilcoxon signed-rank test; Table 2). Severity of dryness, FB sensation, and coldness were improved compared to pretreatment values $(p=0.007,0.006$, and 0.021 , Wilcoxon signed-rank test; Table 3$)$.

\section{Discussion}

Choline has been used to produce acetylcholine, a neurotransmitter in the parasympathetic nervous system [19]. In this retrospective study, we investigated whether oral CA administration improved the symptoms of KCS. Improvement in TBUT, lid hyperemia, symptoms associated with pain, dryness, sensation, and fatigue were identified. Three potential mechanisms may explain the apparent effect of CA administration. First, CA is a surfactant, which may act as an emulsifier, stabilizing the water and lipid layers of the tear film. Next, choline supplementation has been 
reported to attenuate immune inflammation and suppress oxidative stress [19], which contribute to the pathophysiology of KCS. Cholinergic modulation of the immune response presents a new approach to treat inflammation [20]. Acetylcholine-stimulated nicotinic receptors on macrophages cause a concentration-dependent inhibition of proinflammatory cytokine release [21]. Furthermore, choline is a precursor of the parasympathetic neurotransmitter acetylcholine. Muscarinic receptors are present in the cornea conjunctiva [10] and meibomian glands and play a role in wound healing and secretion [9]. Cholinergic transmission profoundly modifies the perception of pain [22]. Cholinergic inhibition of spinal nociceptive transmission [23] leads to the analgesic effects of exogenously administrated cholinergic agonists in neuropathic pain [24]. Antinociceptive effects of cholinergic agonists are associated with gamma-aminobutyric acid-ergic (GABAergic) signaling and nicotinic and muscarinic modulation of nociceptive transmission. Notably, we did not identify any reduction in photophobia in patients enrolled in this study. Another approach may be necessary to reduce the photophobic symptoms of KCS. FSS was not changed because FSS was too low at the baseline. Up to $83.0 \%$ of patients showed no FSS before CA treatment. STT was not changed, although CA is a parasympathomimetic drug. CA may have an effect on KCS mainly through an anti-neuropathic effect in the central nervous system and an enhancement of tear stability as a surfactant in tears. CA may need to be combined with a cholinesterase inhibitor to have a sufficient effect on tear secretion [25].

Polyunsaturated fatty acids supplementation, including omega- 3 and omega- 6 fatty acids, is well known as a nutritional therapy for KCS [26-30], although the main treatment of KCS is topical treatments [31]. Dietary omega-3 and omega- 6 fatty acids supplementation improves the symptoms and inflammation of KCS [32-36]. Omega-6 and omega-3 fatty acids are essential polyunsaturated fatty acids that cannot be synthesized in the body and must be obtained from the diet [32]. Although a higher dietary intake of omega-3 fatty acids is associated with a lower prevalence of dry eye in females [28], a high ratio of omega-6/omega-3 fatty acids ( $>15: 1)$ was associated with a higher than two-fold prevalence of dry eye [28]. The ideal balance of omega-3/omega- 6 fatty acids has been suggested to be 1:2.3 [27]. Omega-3 fatty acids include alpha-linolenic acid (ALA), eicosapentaenoic acid (EPA), and docosahexaenoic acid (DHA) [27]. Oral supplementation of omega-3 fatty acids showed a decrease in the tear evaporation rate, an improvement in dry eye symptoms, and an increase in tear secretion [32,34]. CA might help stabilize the tear film in addition to omega-3 supplementation.

Limitations to this study include its retrospective nature, which can lead to several biases and may not identify some risks or contributing factors, and its small sample size. A sufficiently powered future prospective study could contribute further support for the administration of oral choline for the treatment of KCS. In conclusion, this study identified that oral CA administration is effective in securing tear stability and alleviating the symptoms of dry eye.

Author Contributions: Conceptualization, Y.J.S.; Data curation, J.J.C. and J.S.H.; formal analysis, J.J.C., Y.J.S. and J.S.H.; investigation, J.J.C.; resources, Y.J.S.; writing-original draft preparation, J.J.C. and J.S.H.; Funding acquisition, Y.J.S.; Methodology, Y.J.S.; Software, Y.J.S.; supervision, Y.J.S.; project administration, Y.J.S. All authors have read and agreed to the published version of the manuscript.

Funding: This study was supported by the National Research Foundation (NRF) grant (NRF-2018R1A2B6002251) funded by the Korea government and by Hallym University Research Fund (HURF-2019-05).

Conflicts of Interest: The authors declare no conflict of interest.

\section{References}

1. Shimazaki, J. Definition and Diagnostic Criteria of Dry Eye Disease: Historical Overview and Future Directions. Investig. Ophthalmol. Vis. Sci. 2018, 59, DES7-DES12. [CrossRef]

2. O'Neil, E.C.; Henderson, M.; Massaro-Giordano, M.; Bunya, V.Y. Advances in dry eye disease treatment. Curr. Opin. Ophthalmol. 2019, 30, 166-178. [CrossRef] [PubMed]

3. Galor, A.; Moein, H.R.; Lee, C.; Rodriguez, A.; Felix, E.R.; Sarantopoulos, K.D.; Levitt, R.C. Neuropathic pain and dry eye. Ocul. Surf. 2018, 16, 31-44. [CrossRef] [PubMed] 
4. Stapleton, F.; Alves, M.; Bunya, V.Y.; Jalbert, I.; Lekhanont, K.; Malet, F.; Na, K.S.; Schaumberg, D.; Uchino, M.; Vehof, J.; et al. TFOS DEWS II Epidemiology Report. Ocul. Surf. 2017, 15, 334-365. [CrossRef] [PubMed]

5. Casu, M.A.; Wong, T.P.; De Koninck, Y.; Ribeiro-da-Silva, A.; Cuello, A.C. Aging causes a preferential loss of cholinergic innervation of characterized neocortical pyramidal neurons. Cereb. Cortex 2002, 12, 329-337. [CrossRef]

6. Schliebs, R.; Arendt, T. The cholinergic system in aging and neuronal degeneration. Behav. Brain Res. 2011, 221, 555-563. [CrossRef]

7. Rudchenko, A.; Akude, E.; Cooper, E. Synapses on sympathetic neurons and parasympathetic neurons differ in their vulnerability to diabetes. J. Neurosci. 2014, 34, 8865-8874. [CrossRef]

8. Zhang, X.; M, V.J.; Qu, Y.; He, X.; Ou, S.; Bu, J.; Jia, C.; Wang, J.; Wu, H.; Liu, Z.; et al. Dry Eye Management: Targeting the Ocular Surface Microenvironment. Int. J. Mol. Sci. 2017, 18. [CrossRef]

9. Kam, W.R.; Sullivan, D.A. Neurotransmitter influence on human meibomian gland epithelial cells. Investig. Ophthalmol. Vis. Sci. 2011, 52, 8543-8548. [CrossRef]

10. Liu, S.; Li, J.; Tan, D.T.; Beuerman, R.W. Expression and function of muscarinic receptor subtypes on human cornea and conjunctiva. Investig. Ophthalmol. Vis. Sci. 2007, 48, 2987-2996. [CrossRef]

11. Institute of Medicine (US) Standing Committee on the Scientific Evaluation of Dietary Reference Intakes and Its Panel on Folate, Other B Vitamins, and Choline. Dietary Reference Intakes for Thiamin, Riboflavin, Niacin, Vitamin B6, Folate, Vitamin B12, Pantothenic Acid, Biotin, and Choline; National Academic Press: Washington, WA, USA, 1998. [CrossRef]

12. Parnetti, L.; Mignini, F.; Tomassoni, D.; Traini, E.; Amenta, F. Cholinergic precursors in the treatment of cognitive impairment of vascular origin: Ineffective approaches or need for re-evaluation? J. Neurol. Sci. 2007, 257, 264-269. [CrossRef] [PubMed]

13. Song, G.J.; Suk, K. Pharmacological Modulation of Functional Phenotypes of Microglia in Neurodegenerative Diseases. Front. Aging Neurosci. 2017, 9, 139. [CrossRef] [PubMed]

14. Bartolini, A.; Di Cesare Mannelli, L.; Ghelardini, C. Analgesic and antineuropathic drugs acting through central cholinergic mechanisms. Recent Pat. CNS Drug Discov. 2011, 6, 119-140. [CrossRef] [PubMed]

15. Bron, A.J.; Evans, V.E.; Smith, J.A. Grading of corneal and conjunctival staining in the context of other dry eye tests. Cornea 2003, 22, 640-650. [CrossRef] [PubMed]

16. Schiffman, R.M.; Christianson, M.D.; Jacobsen, G.; Hirsch, J.D.; Reis, B.L. Reliability and validity of the Ocular Surface Disease Index. Arch. Ophthalmol. 2000, 118, 615-621. [CrossRef] [PubMed]

17. Klimek, L.; Bergmann, K.C.; Biedermann, T.; Bousquet, J.; Hellings, P.; Jung, K.; Merk, H.; Olze, H.; Schlenter, W.; Stock, P.; et al. Visual analogue scales (VAS): Measuring instruments for the documentation of symptoms and therapy monitoring in cases of allergic rhinitis in everyday health care: Position Paper of the German Society of Allergology (AeDA) and the German Society of Allergy and Clinical Immunology (DGAKI), ENT Section, in collaboration with the working group on Clinical Immunology, Allergology and Environmental Medicine of the German Society of Otorhinolaryngology, Head and Neck Surgery (DGHNOKHC). Allergo. J. Int. 2017, 26, 16-24. [CrossRef]

18. Salsman, J.M.; Schalet, B.D.; Andrykowski, M.A.; Cella, D. The impact of events scale: A comparison of frequency versus severity approaches to measuring cancer-specific distress. Psychooncology 2015, 24, 1738-1745. [CrossRef]

19. Mehta, A.K.; Singh, B.P.; Arora, N.; Gaur, S.N. Choline attenuates immune inflammation and suppresses oxidative stress in patients with asthma. Immunobiology 2010, 215, 527-534. [CrossRef]

20. Hoover, D.B. Cholinergic modulation of the immune system presents new approaches for treating inflammation. Pharmacol. Ther. 2017, 179, 1-16. [CrossRef]

21. Borovikova, L.V.; Ivanova, S.; Zhang, M.; Yang, H.; Botchkina, G.I.; Watkins, L.R.; Wang, H.; Abumrad, N.; Eaton, J.W.; Tracey, K.J. Vagus nerve stimulation attenuates the systemic inflammatory response to endotoxin. Nature 2000, 405, 458-462. [CrossRef]

22. Naser, P.V.; Kuner, R. Molecular, Cellular and Circuit Basis of Cholinergic Modulation of Pain. Neuroscience 2018, 387, 135-148. [CrossRef] [PubMed]

23. Zhuo, M.; Gebhart, G.F. Tonic cholinergic inhibition of spinal mechanical transmission. Pain 1991, 46, $211-222$. [CrossRef]

24. Matsumoto, M.; Xie, W.; Inoue, M.; Ueda, H. Evidence for the tonic inhibition of spinal pain by nicotinic cholinergic transmission through primary afferents. Mol. Pain 2007, 3, 41. [CrossRef] [PubMed] 
25. Scapicchio, P.L. Revisiting Choline Alphoscerate Profile: A New, Perspective, Role in Dementia? Int. J. Neurosci. 2013, 123, 444-449. [CrossRef]

26. Yagci, A.; Gurdal, C. The role and treatment of inflammation in dry eye disease. Int. Ophthalmol. 2014, 34, 1291-1301. [CrossRef]

27. Roncone, M.; Bartlett, H.; Eperjesi, F. Essential fatty acids for dry eye: A review. Contact Lens Anterior Eye 2010, 33, 49-54. [CrossRef]

28. Miljanović, B.; Trivedi, K.A.; Dana, M.R.; Gilbard, J.P.; Buring, J.E.; Debra A Schaumberg, D.A. Relation between dietary n-3 and n-6 fatty acids and clinically diagnosed dry eye syndrome in women. Am. J. Clin. Nutr. 2005, 82, 887-893. [CrossRef]

29. Sheppard, J.D.; Singh, R.; McClellan, A.J.; Weikert, M.P.; Scoper, S.V.; Joly, T.J.; Whitley, W.O.; Kakkar, E.; Pflugfelder, S.C. Long-term supplementation with n-6 and n-3 PUFAs improves moderate to severe keratoconjunctivitis sicca: A randomized double-blind clinical trial. Cornea 2013, 32, 1297-1304. [CrossRef]

30. Jackson, M.A.; Burrell, K.; Gaddie, I.B.; Richardson, S.D. Efficacy of a new prescription-only medical food supplement in alleviating signs and symptoms of dry eye, with or without concomitant cyclosporine A. Clin. Ophthalmol. 2011, 5, 1201-1206. [CrossRef]

31. Alves, M.; Fonseca, E.C.; Alves, M.F.; Malki, L.T.; Arruda, G.V.; Reinach, P.S.; Rocha, E.M. Dry eye disease treatment: A systematic review of published trials and a critical appraisal of therapeutic strategies. Ocul. Surf. 2013, 11, 181-192. [CrossRef]

32. Kangari, H.; Eftekhari, M.H.; Sardari, S.; Hashemi, H.; Salamzadeh, J.; Ghassemi-Broumand, M.; Khabazkhoob, M. Short-term consumption of oral omega-3 and dry eye syndrome. Ophthalmology 2013, 120, 2191-2196. [CrossRef] [PubMed]

33. Bhargava, R.; Kumar, P.; Kumar, M.; Mehra, N.; Mishra, A. A randomized controlled trial of omega-3 fatty acids in dry eye syndrome. Int. J. Ophthalmol. 2013, 6, 811-816. [PubMed]

34. Wojtowicz, J.C.; Butovich, I.; Uchiyama, E.; Agee, S.; McCulley, J.P. Pilot, prospective, randomized, double-masked, placebo-controlled clinical trial of an omega-3 supplement for dry eye. Cornea 2011, 30, 308-314. [CrossRef] [PubMed]

35. Brignole-Baudouin, F.; Baudouin, C.; Aragona, P.; Rolando, M.; Labetoulle, M.; Pisella, P.J.; Barabino, S.; Siou-Mermet, R.; Creuzot-Garcher, C. A multicentre, double-masked, randomized, controlled trial assessing the effect of oral supplementation of omega- 3 and omega- 6 fatty acids on a conjunctival inflammatory marker in dry eye patients. Acta Ophthalmol. 2011, 89, 591-597. [CrossRef]

36. Bhargava, R.; Kumar, P.; Phogat, H.; Kaur, A.; Kumar, M. Oral omega-3 fatty acids treatment in computer vision syndrome related dry eye. Contact Lens Anterior Eye 2015, 38, 206-210. [CrossRef] 